\title{
Analysis of Effervescence during Hydrosilylation Curing
}

\author{
Takahisa Iwahara, ${ }^{*}$ Masato Kusakabe, Makoto ChiBa, \\ and Kazuya Yonezawa
}

Central Research Laboratories, Research Institute, Kaneka Corporation, 1-2-80 Yoshida-cho, Hyogo-ku, Kobe 652, Japan

(Received June 2, 1993)

\begin{abstract}
In the novel hydrosilylation curing system, derived from an $\alpha, \omega$-bis $(2,4,6,8$ tetramethylcyclotetrasiloxan-2-yl) carbon chain crosslinker 1 and allyl-group-end-blocked oligomer 2, effervescence phenomena during curing were examined. We found that the main component of the gas formed was propylene when 1 and 2 were heated in the presence of $\mathrm{H}_{2} \mathrm{PtCl}_{6}$ for cure and that the amount of the gas was largely dependent on the structure of allyl functionality; in the system with allyl carbonate or allyl ester gas genaration was very distinctive and propylene formation was dominant well over the normal hydrosilylation.

KEY WORDS Effervescence / Hydrosilylation Curing / Pt-Catalyst / $\alpha, \omega$-bis(2,4,6,8-tetramethylcyclotetrasiloxan-2-yl) Carbon Chain Crosslinker / Allyl-Group-End-Blocked Oligomer / Propylene Formation /
\end{abstract}

We successfully applied the hydrosilylation reaction to the new organic-oligomer-based curing system as shown in Scheme $1 .^{1-3}$ But effervescence still took place in some cases during curing in spite of the good miscibility of the two components, 1 and 2. The cured substances looked like foam with mechanicallyweakened strength.

This paper describes the unexpected effervescence phenomenon from the polyhydrosiloxane-based hydrosilylation curing system and refers to the mechanism of gas formation.

\section{EXPERIMENTAL}

\section{Reagents}

Cyclohydrotetrasiloxanes, $\left[\mathrm{CH}_{3} \mathrm{Si}(\mathrm{H}) \mathrm{O}\right]_{4}$ (3), LS-8600 (Shin-etsu Chemical Industry) and $\left[\mathrm{CH}_{3} \mathrm{Si}(\mathrm{H}) \mathrm{O}\right]\left[\left(\mathrm{CH}_{3}\right)_{2} \mathrm{SiO}\right]_{3} \quad(5), \mathrm{XC}-95$ (Toshiba silicone) were used as received. Allylcontaining compounds, 1,9-decadiene (Shell) 4a, diallyl isophthalate (Wako, first grade) 4c, and diethylene glycol diallyl carbonate $\mathbf{4 d}$
(Mitsui Petrochemical, RAV-7N) were employed without further purification. Bisphenol A diallyl ether $\mathbf{4 b}$ was synthesized. ${ }^{1}$ Chloroplatinic acid solution $(10 \mathrm{wt} \%)$ was prepared by dissolving $1.0 \mathrm{~g}$ of $\mathrm{H}_{2} \mathrm{PtCl}_{6} \cdot 6 \mathrm{H}_{2} \mathrm{O}$ in $1 \mathrm{ml}$ of ethanol and $9 \mathrm{ml}$ of 1,2-dimethoxyethane. Diluting the $10 \mathrm{wt} \%$ solution by 10 -fold with the same solvent mixture gave $1 \mathrm{wt} \%$ solution.

\section{Collection and Analysis of the Gas Formed during Curing}

A $100-\mathrm{ml}$ round-bottomed flask was equipped with a 3-way stopcock with a septum cap and a Teflon stirrer bar. A plastic-made gas-collection bag with 2-way stopcock was connected to the flask at the 3-way stopcock by meas of silicon tube. The system of $\mathbf{3 / 4 d}$ (entry No.4 in Table I) is an example and explained here. The reaction apparatus was first pumped to exclude the air in it and the 2-way stopcock of the collection bag was closed. From the 3-way stopcock fitted on the flask, $0.73 \mathrm{~g}(3.0 \mathrm{mmol})$ of $3,0.99 \mathrm{~g}(3.6 \mathrm{mmol})$

\footnotetext{
* To whom all correspondence should be addressed.
} 

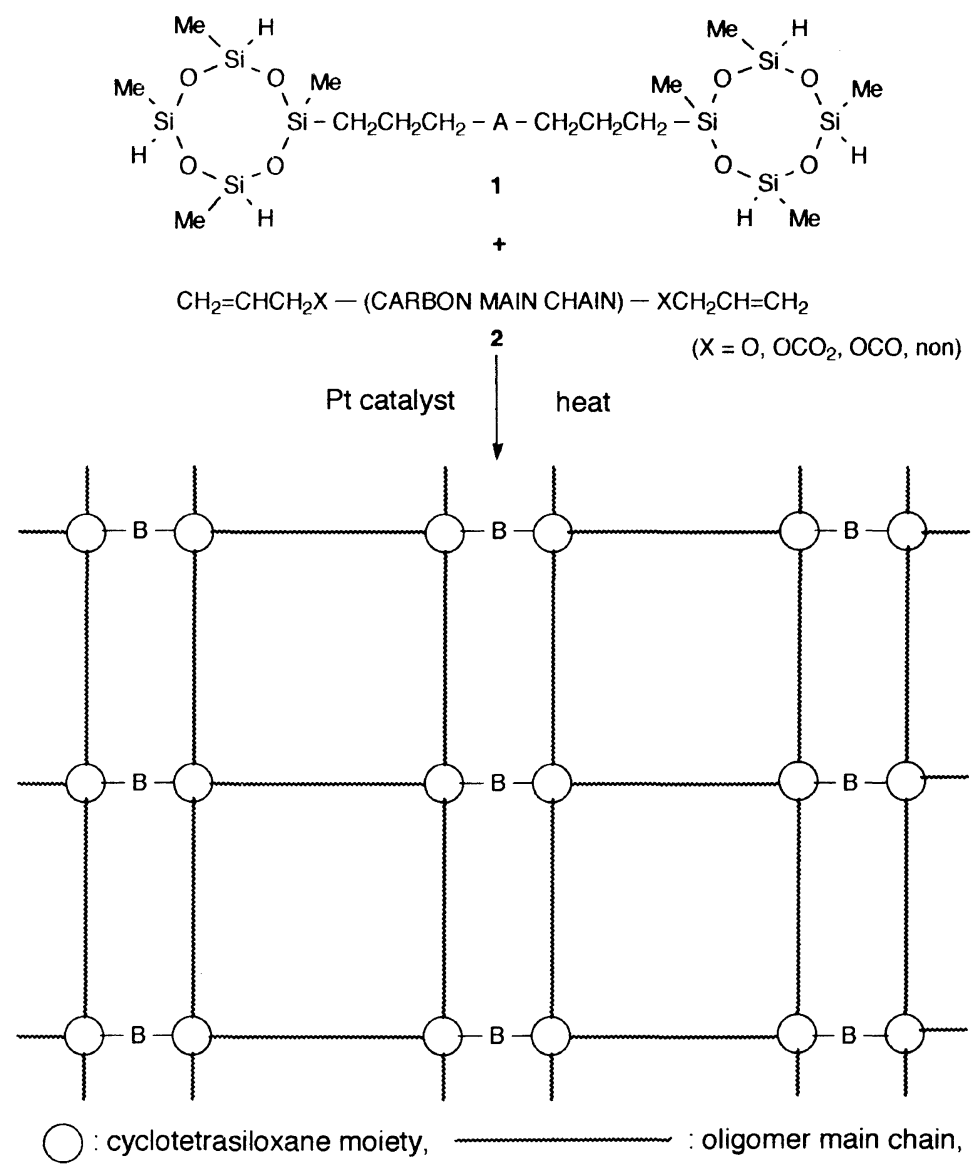

B: organic moiety of $\mathbf{1}$ between the cyclotetrasiloxane structures.

Scheme 1. Hydrosilylation curing of the novel organic-oligomer-based system.

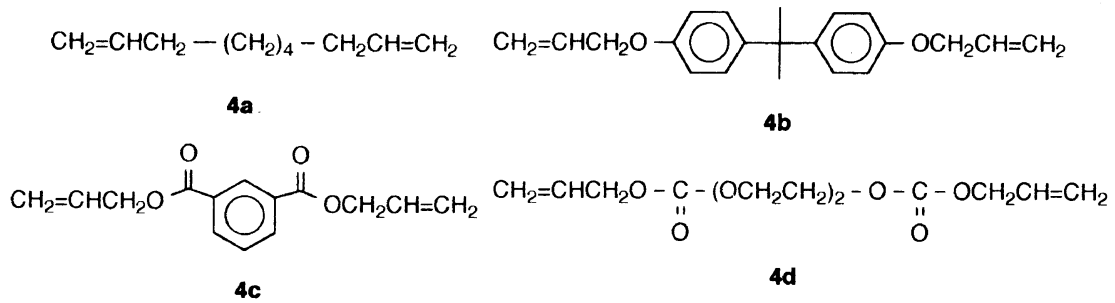

of $4 \mathrm{~d}$, and $18.8 \mu \mathrm{l}\left(3.6 \times 10^{-3} \mathrm{mmol}, 5 \times 10^{-4}\right.$ mol relative to $1 \mathrm{~mol}$ of allyl) of $10 \mathrm{wt} \%$ chloroplatinic acid catalyst solution were injected into the flask by a syringe at room temperature.
The mixture was stirred and put in an oil bath at $80^{\circ} \mathrm{C}$, and at the same time the 2-way stopcock at the collection bag was opened. After a $1-2 \mathrm{~min}$ induction period, the reaction suddenly started and gas was collected in the 
Analysis of Effervescence during Hydrosilylation Curing

Table I. Model system for effervescence

\begin{tabular}{|c|c|c|c|}
\hline \multirow{2}{*}{$\begin{array}{c}\text { Entry } \\
\text { No. }\end{array}$} & Allyl-containing compounds & $\left.\mathrm{CH}_{3}(\mathrm{H}) \mathrm{SiO}\right]_{4}$ & $10 \mathrm{wt} \% \mathrm{Pt}$ cat. soln. \\
\hline & $\mathrm{g}(\mathrm{mmol})$ & $\mathrm{g}(\mathrm{mmol})$ & $\mu \mathrm{l}(\mathrm{mmol})$ \\
\hline 1 & 4a $9.96(72.2)$ & $7.25(30.1)$ & $37.3\left(7.2 \times 10^{-3}\right)$ \\
\hline 2 & 4b $9.96(32.3)$ & $3.89(16.2)$ & $16.8\left(3.2 \times 10^{-3}\right)$ \\
\hline 3 & 4c $1.38(5.6)$ & $0.67(2.8)$ & $29.0\left(5.6 \times 10^{-3}\right)$ \\
\hline 4 & 4d $\quad 0.99(3.6)$ & $0.73(3.0)$ & $18.8\left(3.6 \times 10^{-3}\right)$ \\
\hline
\end{tabular}

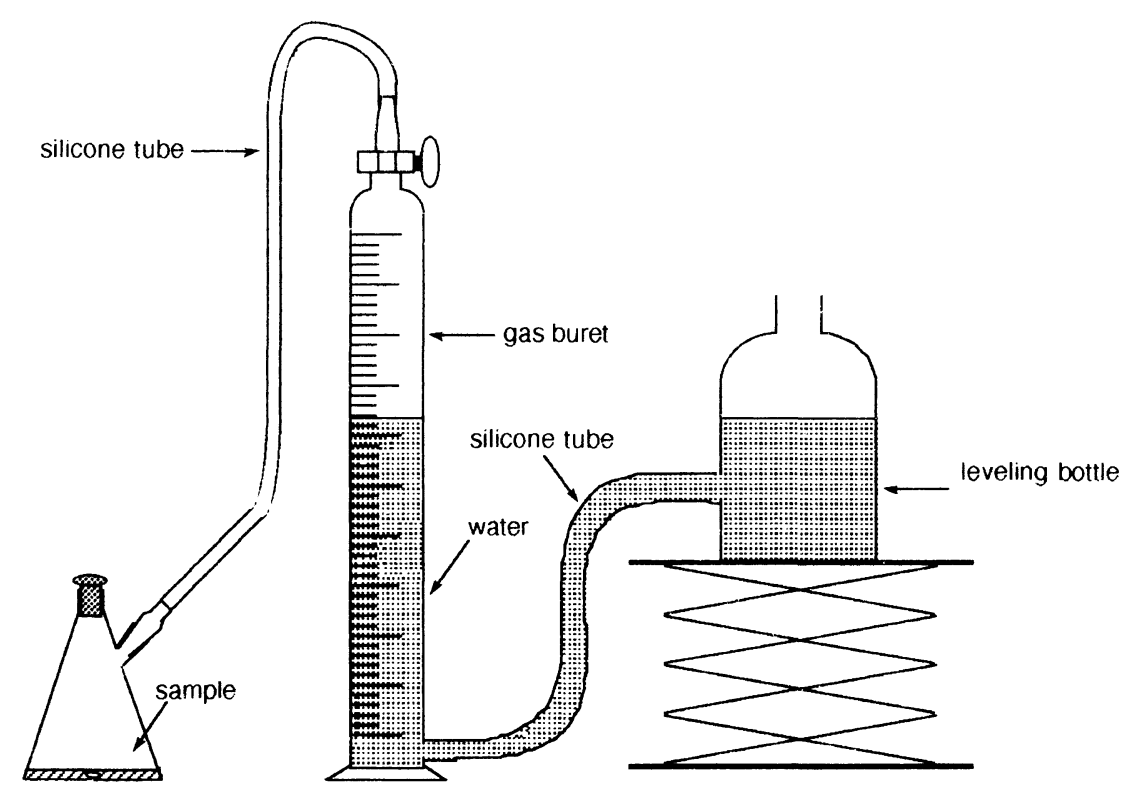

Figure 1. Apparatus for volume measurements of gas formed.

bag. The mixture in the flask turned into a foam. The gas collected was sampled with a gas syringe and submitted to GC and GCMS analysis.

GC conditions were as follows: (i) for detection of propylene, ethanol and DME, Gaschropack 54 (from GL Science, $3.2 \mathrm{~mm} \phi \times$ $1 \mathrm{~m}$ ) was used at $80^{\circ} \mathrm{C}$ of column temperature with FID; (ii) for detection of hydrogen, Molecular sieve 13X (from GL Science, 3.2 $\mathrm{mm} \phi \times 2.1 \mathrm{~m})$ was used at $40^{\circ} \mathrm{C}$ of column temperature with TCD.

GCMS conditions were as follows: Hewlett Packered GCMS-5985B; PEG (10\%), $2 \mathrm{~mm} \times$ $8 \mathrm{ft}$. (glass column); $100^{\circ} \mathrm{C}$, helium $14 \mathrm{ml}$ $\min ^{-1}$; injection, $200^{\circ} \mathrm{C}$; ion source, $250^{\circ} \mathrm{C}$; range of mass measured $=1-150 \mathrm{amu}$; voltage of electronmultiplier $=2200 \mathrm{eV}$; sample volume for an injection $=0.5 \mathrm{ml}$.

\section{Quantitative Volume Measurement of the Gas}

\section{Formed}

The apparatus is as shown in Figure 1. In the $100-\mathrm{ml}$ flask were placed certain amounts of an allyl-containing compound $4, \mathrm{CCH}_{3}(\mathrm{H})$ $\mathrm{SiO}]\left[\left(\mathrm{CH}_{3}\right)_{2} \mathrm{SiO}\right]_{3}(\mathbf{5})$, and the chloroplatinic acid catalyst solution (Table II) at room temperature and a glass stopper was fitted on the flask. The mixture was well stirred and the water level in the gas buret was recorded. The 
T. IWAHARA et al.

Table II. Measurements of gas evolved

\begin{tabular}{|c|c|c|c|c|}
\hline \multirow{2}{*}{$\begin{array}{c}\text { Entry } \\
\text { No. }\end{array}$} & \multicolumn{2}{|c|}{ Allyl-containing compounds } & \multirow{2}{*}{$\frac{\left[\mathrm{CH}_{3}(\mathrm{H}) \mathrm{SiO}\right]\left[\left(\mathrm{CH}_{3}\right)_{2} \mathrm{SiO}\right]_{3}}{\mathrm{~g}(\mathrm{mmol})}$} & \multirow{2}{*}{$\frac{10 \mathrm{wt} \% \text { Pt cat. soln. }}{\mu \mathrm{l}(\mathrm{mmol})}$} \\
\hline & & $\mathrm{g}(\mathrm{mmol})$ & & \\
\hline 5 & $4 b$ & $0.50(1.62)$ & $0.92(3.26)$ & $16.8\left(3.24 \times 10^{-3}\right)$ \\
\hline 6 & $4 c$ & $0.50(1.89)$ & $1.15(4.01)$ & $21.1\left(4.07 \times 10^{-3}\right)$ \\
\hline 7 & 4d & $0.51(1.86)$ & $1.05(3.72)$ & $18.5\left(3.57 \times 10^{-3}\right)$ \\
\hline
\end{tabular}

flask was then put in an oil bath at $70^{\circ} \mathrm{C}$. Gas formation abruptly occurred after a $1-2 \mathrm{~min}$ induction period and completed within 5-6 min. During and after gas evolution, the pressure in the reaction system was kept equal to the atmosphere. The reaction system was allowed to stand for another $20-30 \mathrm{~min}$ to cool the temperature in the system to the room temperature and the water level in the gas buret was again recorded to obtain the volume of the gas evolved $(n=2)$.

\section{Synthesis of Di-n-3-butenyl Isophthalate}

A 500-ml 4-necked round-bottomed flask was equipped with a motor-driven stirrer, a 200-ml pressure-equalized dropping funnel, a reflux condenser with a 3-way stopcock, and a thermometer. The air in the reaction system was substituted with nitrogen and $10.0 \mathrm{~g}$ $(0.139 \mathrm{~mol})$ of 3 -buten-1-ol and $32.98 \mathrm{~g}(0.417$ mol) of pyridine were placed in the flask under nitrogen. The dropping funnel was then charged with a solution of $13.41 \mathrm{~g}(0.066 \mathrm{~mol})$ of isophthaloyl chloride dissolved in $50 \mathrm{ml}$ of dry tetrahydrofuran (THF). The THF solution was added to the flask in an oil bath at $65^{\circ} \mathrm{C}$ over $1.5 \mathrm{~h}$. After completion of the addition, the reaction mixture was stirred at $65^{\circ} \mathrm{C}$ for another $1.5 \mathrm{~h}$.

The reaction mixture was filtered under reduced pressure to remove the pyridinium chloride formed and the filtrate was washed with deionized water $(50 \mathrm{ml} \times 3)$ and dried over anhydrous magnesium sulfate. After addition of a small amount of toluene, evaporation of the volatile fractions under reduced pressure gave $15.73 \mathrm{~g}$ (crude yield: $87 \%$ ) of a crude product as an oil. It was then submitted to column chromatography (silica gel C-200 from Wako Pure Chemical Co., AcOEt/Hexane= $1 / 20-1 / 16$ as the eluents) for purification.

${ }^{1} \mathrm{H} \mathrm{NMR}\left(300 \mathrm{MHz}, \mathrm{CDCl}_{3}\right) \delta 2.50(4 \mathrm{H}, \mathrm{dt}$, $\left.J=7.3,7.3 \mathrm{~Hz},-\mathrm{OCH}_{2} \mathrm{CH}_{2} \mathrm{CH}=\mathrm{CH}_{2}\right), 4.34$ $\left(4 \mathrm{H}, \mathrm{t}, J=7.3 \mathrm{~Hz},-\mathrm{OC}_{2} \mathrm{CH}_{2} \mathrm{CH}=\mathrm{CH}_{2}\right), 5.07$ $(2 \mathrm{H}, \mathrm{dd}, J=10.4 \mathrm{~Hz}$ and a very small value, $-\mathrm{OCH}_{2} \mathrm{CH}_{2}-\mathrm{CH}=\mathrm{CH}_{2}$, cis $), 5.15(2 \mathrm{H}, \mathrm{dd}, \mathrm{J}=$ $17.7 \mathrm{~Hz}$ and a very small value, $-\mathrm{OCH}_{2} \mathrm{CH}_{2} \mathrm{CH}$ $=\mathrm{C}_{2}$, trans $), 5.84(2 \mathrm{H}$, ddt, $J=17.7,10.4$, $\left.7.2 \mathrm{~Hz},-\mathrm{OCH}_{2} \mathrm{CH}_{2} \mathrm{CH}=\mathrm{CH}_{2}\right), 7.46(1 \mathrm{H}, \mathrm{t}$, $J=9.4 \mathrm{~Hz}), 8.45(2 \mathrm{H}, \mathrm{dd}, J=9.4 \mathrm{~Hz}$ and a very small value), $8.63(1 \mathrm{H}, \mathrm{t}, J=$ a very small value $)$. IR (neat, $\left.\mathrm{cm}^{-1}\right) 1720\left(v_{\mathrm{C}=\mathrm{o}}\right), 1640\left(v_{\mathrm{C}=\mathrm{C}}\right)$.

\section{Preparation of Cured Materials by Use of} Di-n-3-butenyl Isophthalate

$0.50 \mathrm{~g}$ (unsaturated content $=3.65 \mathrm{mmol}$ ) of di- $n$-3-butenyl isophthalate, $0.55 \mathrm{~g}$ ( $\mathrm{SiH}$ content $=3.65 \mathrm{mmol} ; 0.664 \mathrm{~mol} / 100 \mathrm{~g}$ ) of crosslinker $1 \mathrm{a}$, and $5 \mu \mathrm{l}\left(2 \times 10^{-5} \mathrm{~mol}\right.$ relative to $1 \mathrm{~mol}$ of the unsaturated bonds) of $1 \mathrm{wt} \%$ chloroplatinic acid catalyst solution were weighed in a stainless small pan and well mixed. At this point, the composition was cloudy. It was cured at $100^{\circ} \mathrm{C}$ for $15 \mathrm{~min}$ to give a colorless clear brittle substance without bubble incorporation.

\section{RESULTS AND DISCUSSION}

Hydrogen evolution has been well known for the $\mathrm{SiH}$ functionality, besides hydrosilylation reaction, as the following reactions; those reactions are actually observed in addition-type polyorganosiloxane oligomers. ${ }^{4}$ 


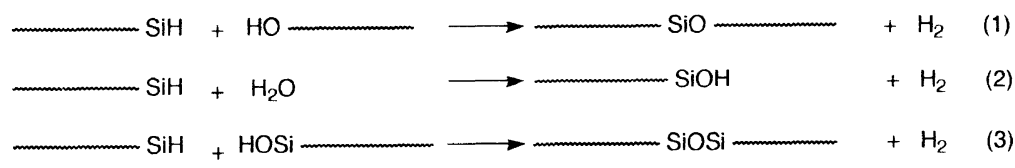

In the novel addition-type-curing system as shown in Scheme 1, if a compound promoting the reactions (1)-(3) is accidentally mixed, hydrogen evolution may occur to lead to effervescence. The same undesirable side reactions may happen in the new curing system because the same functionalities as in the addition-type silicone oligomers get involved with curing. Even after careful exclusion of the compounds ( $\mathrm{HO}$ mm $, \mathrm{H}_{2} \mathrm{O}, \mathrm{HOSimmm}$ ) related to reactions (1)-(3), effervescence was still observed in some cases. An alternative mechanism other than equations (1)-(3) may thus cause the problem.

\section{(1) Analysis of the Gas Formed during Curing}

We employed low-molecular-weight compounds whose functional-group density was high enough for analysis of the reactions during curing. For the SiH-containing compound, 2,4,6,8-tetramethylcyclotetrasiloxane $\left[\mathrm{CH}_{3}(\mathrm{H}) \mathrm{SiO}\right]_{4}(3)$, whose structure was the same as that in SiH-containing crosslinkers $\mathbf{1}$, was adopted. For allyl alkylene-, allyl ether-, allyl ester-, and allyl carbonate-containing compounds, the following were employed: 1,9-decadiene 4a, bisphenol A diallyl ether $\mathbf{4 b}$, diallyl isophthalate $\mathbf{4 c}$, and diethyleneglycol diallyl carbonate $\mathbf{4 d}$.

Certain amounts of 3, 4, and the platinum catalyst solution were mixed $(\mathrm{SiH} / \mathrm{allyl} / \mathrm{Pt}$ $($ molar ratio $\left.)=1 / 1 / 5 \times 10^{-4}\right)$ and reacted at $80^{\circ} \mathrm{C}$ for $5 \mathrm{~min}$. During the reaction the gas formed was collected and analyzed by gas chromatography and GC-mass spectroscopy (System of $3 / 4 a, 3 / 4 b, 3 / 4 c, 3 / 4 d$ were named entry No, 1, 2, 3, and 4, respectively).

The following were revealed:

- The volume of the gas formed was dependent on the structure of the allyl functionality;

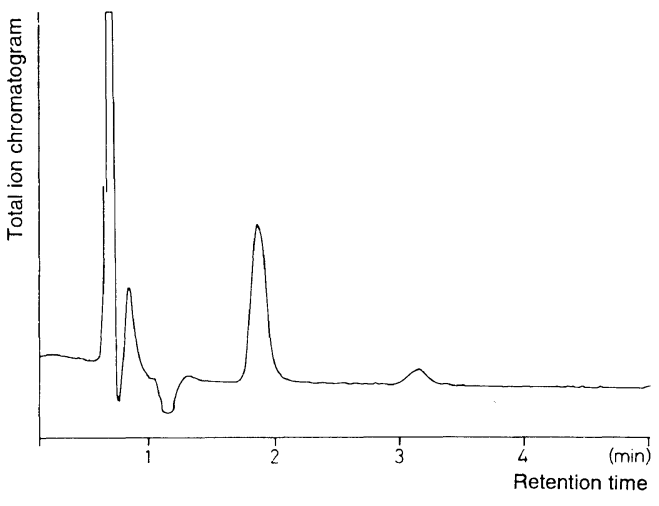

Figure 2. GCMS total ion chromatogram of entry 3 $(\mathbf{3} / \mathbf{4 c})$ in Table I. 1st peak, propylene; 2nd peak, unknown, same mass pattern as that of the 1st one; 3rd peak, 1,2-dimethoxyethane (DME) from the Pt cat. solution.

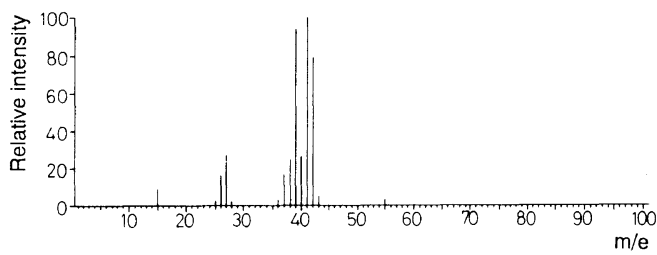

Figure 3. Mass spectrum of the first peak in entry 3 $(3 / 4 c)$.

allyl carbonate $>$ allyl ester $>$ allyl ether $>$ allyl alkylene.

- Except for entry No.1, the formation of a gas with molecular weight of 42 was observed as the main component of the gas. It was identified as propylene by GCMS (Figures 2 and 3) and comparison of its retention time on $\mathrm{GC}$ with that of an authentic sample.

- Formation of hydrogen gas was $3.6 \%$ for entry No.4, whose total gas volume was large.

- Dimethoxyethane used as solvent for the Pt catalyst, was observed in the gas evolved. 
(2) Measurement of the Gas Evolved and Discussion on the Mechanism

To examine how much extent of the gas evolution took place as side reaction(s) in the four systems (entry No. 1-4), the volume of the gas formed during the reaction was measured. Certain amounts of $4,\left[\mathrm{CH}_{3}(\mathrm{H})\right.$ $\mathrm{SiO}]\left[\left(\mathrm{CH}_{3}\right)_{2} \mathrm{SiO}\right]_{3}(5)$, and the $\mathrm{Pt}$ catalyst solution $\left(\mathrm{SiH} /\right.$ allyl $\left./ \mathrm{Pt}=1 / 1 / 1 \times 10^{-3}\right)$ were reacted at $70^{\circ} \mathrm{C}$. For the $\mathrm{SiH}$-containing compound, 5 was employed to get the reactions completed in the liquid phase. Gas evolution abruptly took place after $1-2 \mathrm{~min}$ induction period and was completed within 5-6 min.

The results are shown in Table III. We recomfirmed that the amount of the gas evolved was largely dependent on the structure of the allyl functionality. The evolution of as much as about $60 \%$ of gas relative to allyl groups was observed when allyl carbonate-containing compound 4d was used, and the main component of the gas was propylene. The system with 1,9-decadiene 4a, though not given in Table III, did not produce a measurable amount of gas.

${ }^{1} \mathrm{H}-{ }^{1} \mathrm{H}$ COSY NMR analysis (Figure 4) for the products of entry 7 in Table III was carried out (Figure 4). We can see the complexity of the reactions in entry No.7, reaction of $\mathbf{4 d}$ with 5. Reactions that likely occurred are shown in Scheme 2.

Formation of the normal hydrosilylation products (A) was confirmed by the signal of the trimethylene units $\left(-\mathrm{SiC}_{2} \mathrm{CH}_{2} \mathrm{CH}_{2}\right.$ $\mathrm{OCO}_{2}^{-}$), whose chain order was assured by the COSY NMR. We observed signals due to the hydrosilylation product (C) $\left[\left(\mathrm{CH}_{3}\right)_{2} \mathrm{SiO}_{3}\right.$ $\left[\mathrm{CH}_{3}\left(\mathrm{CH}_{3} \mathrm{CH}_{2} \mathrm{CH}_{2}\right) \mathrm{SiO}\right](6)$ of the propylene, produced by reductive cleavage of the allylic $\mathrm{C}-\mathrm{O}$ bond (B). Thermal polymerization of the allyl carbonate moieties (D) likely occurred, because of the complete disappearance of the allylic signals in spite of the propylene formation corresponding to $60 \%$ of the $\mathrm{SiH}$ functionality of $\mathbf{5}$ and viscosity increase of the reaction mixture as well as partial gelation.
Table III. Measurements of gas evolved

\begin{tabular}{ccccc}
\hline \multirow{2}{*}{$\begin{array}{c}\text { Entry } \\
\text { No. }\end{array} \begin{array}{c}\text { Amounts } \\
\text { of allyl/ } \\
\text { mmol }\end{array}$} & $\begin{array}{c}\text { Type of the allyl- } \\
\text { functionality } \\
\text { of } 4\end{array}$ & Gas evolved & $\begin{array}{c}\% \text { rel. } \\
\text { to } \\
\text { allyl }\end{array}$ \\
\hline 5 & 3.25 & Allyl ether & $0.5(0.026)$ & 0.8 \\
6 & 3.78 & Allyl ester & $32.9(1.33)$ & 35 \\
7 & 3.72 & Allyl carbonate & $55.2(2.23)$ & 60
\end{tabular}

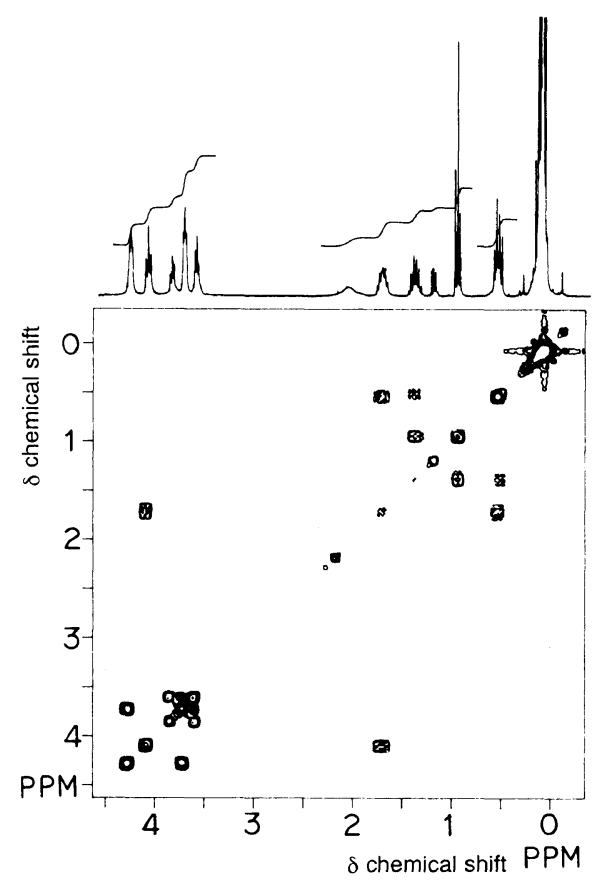

Figure 4. ${ }^{1} \mathrm{H}-{ }^{1} \mathrm{H}$ COSY NMR spectrum of entry 7 (4d/5) after reaction.

The $\mathrm{SiH}$ consumption of $\mathbf{5}$ in the reaction with $\mathbf{4 d}$ can be roughly summarized on the basis of the signal intensities of $-\mathrm{SiCH}_{2} \mathrm{CH}_{2} \mathrm{CH}_{3}$ (1.4 ppm), $-\mathrm{SiCH}_{2} \mathrm{C}_{2} \mathrm{CH}_{2} \mathrm{OCO}_{2}-(1.7 \mathrm{ppm})$ and volume of the gas evolved: the propylene formation, $60 \%$; hydrosilylation product of propylene (6), $26 \%$; the normal hydrosilylation products, $14 \%$. The results clearly show that propylene formation was significantly dominant over the normal hydrosilylation reaction.

In the well-known addition type polysiloxane system, which is cured by hydrosilylation, the $\mathrm{SiH}$-related condensation reactions 


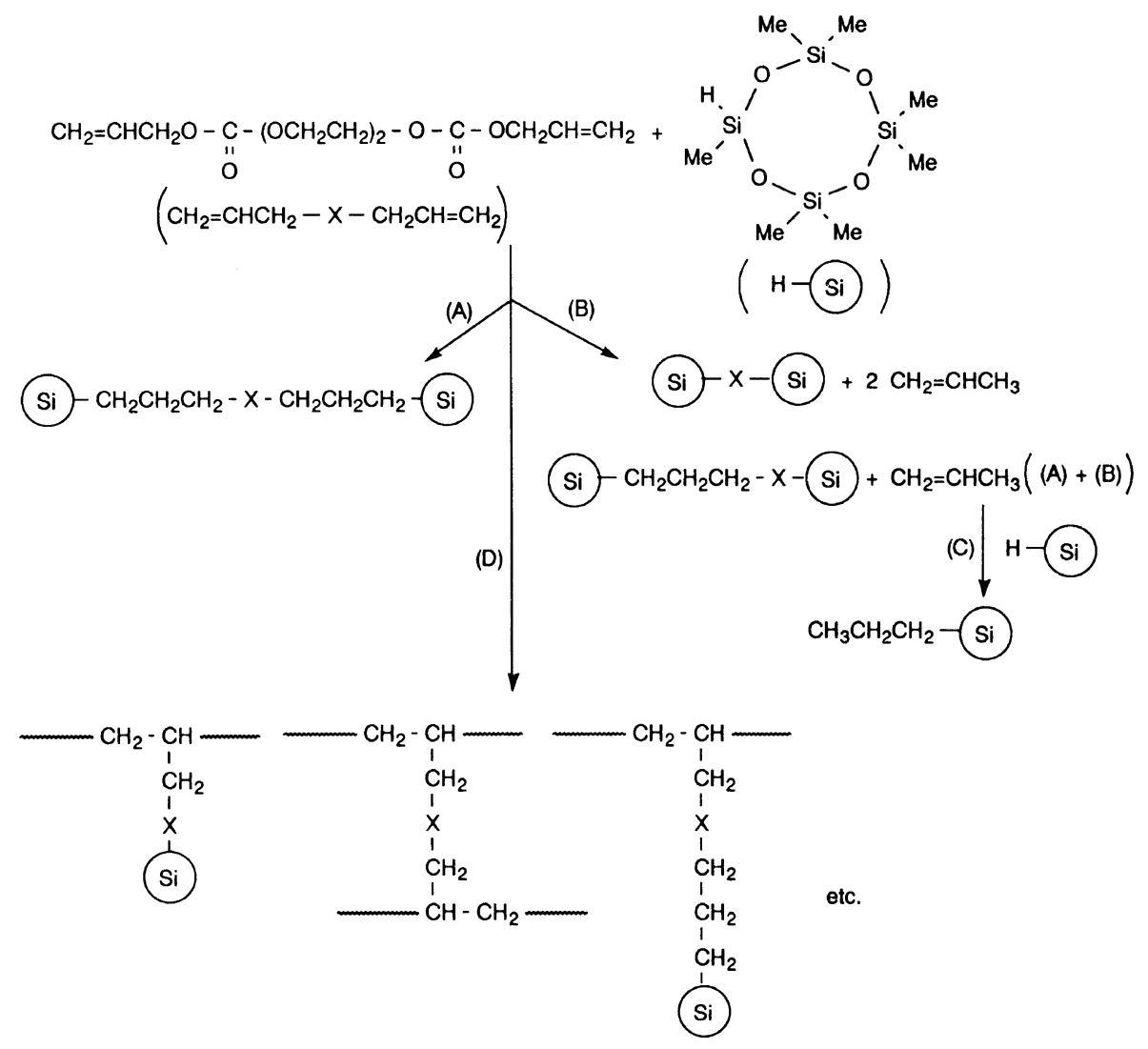

(A) Normal hydrosilylation, (B) Formation of propylene,

(C) Hydrosilylation of propylene,

(D) Thermal polymerization of the allyl carbonate moieties

Scheme 2. Reactions of $\mathbf{4 d}$ with 5 likely occurring.

(1) - (3) actually cause effervescent phenomena during curing. ${ }^{4}$ In this system, the counterpart for the SiH-containing polysiloxane is a vinylsubstituted polysiloxane, which seldom causes a side reaction because of the stable vinylic $\mathrm{Si}-\mathrm{C}$ bond under the curing conditions. Thus effervescence does not occur only when compounds which induce the reactions (1)-(3) are excluded.

Among the allyl-type olefins employed as the reaction partner of the new $\mathrm{SiH}$-containing crosslinkers 1, the allyl carbonate and aromatic allyl ester turned out to cause an unexpectedly serious problem of the propylene formation during curing.

Propylene evolution occurred through hydrosilylation reactions of allyl chloride, bromide and acetate and some related esters. ${ }^{5}$ Reduction to propylene of these compounds has been interpreted (i) either in terms of formation of a $\pi$-allyl complex by transfer of chlorines rather than hydrogen to platinum (eq $5, \mathrm{X}=\mathrm{Cl}$ ), or (ii) by isomerization reaction (4) of the Chalk-Harrod scheme (eq 4), in which after attachment to platinum of a secondary carbon atom of the chloropropyl group, reversion to a $\pi$-complex involves migration of chlorine (not hydrogen) to platinum (eq 6, 


$$
{ }_{(-4)}^{\mathrm{X}=\mathrm{Cl}) .^{6}}
$$

In the system containing either diallyl isophthalate $\mathbf{4 c}$ or diethyleneglycol diallyl carbonate 4d whose allyl moiety is linked to an electron-withdrawing group (oxycarbonyl group) comparable to halogen, the same types of reactions as eq 5 or eq 6 may likely occur to lead the propylene formation.

In the system containing diallyl ether of bisphenol $\mathbf{A} \mathbf{4 b}$, the addition of $\mathrm{Si}-\mathrm{H}$ of $\left[\mathrm{CH}_{3}(\mathrm{H}) \mathrm{SiO}_{4}\right.$ (3) to the p-isopropylidenephenoxy attached allyl functionality fortunately proceeded almost normally. That is because the reaction selectivity of hydrosilylation of phenyl allyl ether seems very sensitive to the substrates employed. Although reaction with $\mathrm{MeSiCl}_{2} \mathrm{H}$ gave a mixture of several products including the normal addition product, addition of trialkoxysilane proceeded normally. ${ }^{7}$

An allyl alkylene-type olefin 4a does not have an electronegative group that can migrate to the platinum to cause propylene formation via the similar pathway to eq 6 or eq 7 .

\section{(3) Countermeasure for Effervescence}

To avoid the propylene formation probably via the similar reaction pathway to eq 5 or 6 , insertion of a methylene spacer between the allyl and the oxycarbonyl group was examined. Di-n-3-butenyl isophthalate was prepared as shown in eq 7.<smiles>C=CCCCOC(=O)c1cccc(C(=O)OCCC=CC)c1</smiles>

The di- $n$-3-butenyl isophthalate prepared and SiH-containing crosslinking reagent $\mathbf{1 a}$, and chloroplatinic acid catalyst solution $\left(\mathrm{SiH} / \mathrm{allyl} / \mathrm{Pt}=1 / 1 / 2 \times 10^{-5}\right)$ were mixed and cured $\left(100^{\circ} \mathrm{C} / 15 \mathrm{~min}\right)$ to give a clear and homogeneously crosslinked substance without effervescence.

Acknowledgement. We are grateful to Makoto Kumada, Emeritus Professor of Kyoto University, for his kind assistance and correcting our manuscript.

\section{REFERENCES}

1. T. Iwahara, M. Kusakabe, M. Chiba, and K. Yonezawa, Polym. J., 25, 379 (1993).

2. T. Iwahara, M. Kusakabe, M. Chiba, and K. Yonezawa, J. Appl. Polym. Sci., in press.

3. T. Iwahara, M. Kusakabe, M. Chiba, and K. Yonezawa, J. Polym. Sci., A, Polym. Chem., 31, 2617 (1993).

4. Such phenomena are actually observed in additiontype-curing silicone; Special Silicone, a catalog from Chisso p10, Fine Chemical Division, Third Division (1983).

5. J. W. Ryan and J. L. Speier, J. Am. Chem. Soc., 86, 895 (1964); A. G. Smith, J. W. Ryan, and J. L. Speier, J. Org. Chem., 27, 2183 (1962).

6. A. G. Chalk and J. F. Harrod, J. Am. Chem. Soc., 87, 16 (1965).

7. E. Lukevics, W. V. Belyakova, M. G. Pomerantseva, and M. G. Voronkov, J. Organomet. Chem. Library, 5, Hydrosilylation. Recent Achievements, 44 (1977). 